Frankreich-Jahrbuch 1999 


\section{Frankreich-Jahrbuch 1999}

Politik, Wirtschaft, Gesellschaft, Geschichte, Kultur

Herausgeber:

Deutsch-Französisches Institut

in Verbindung mit

Lothar Albertin - Wolfgang Asholt .

Hans Manfred Bock

Marieluise Christadler

Ingo Kolboom · Adolf Kimmel

Robert Picht · Henrik Uterwedde

Redaktion: Joachim Schild

Leske + Budrich, Opladen 1999 
ISBN 978-3-322-95144-1

DOI 10.1007/978-3-322-95143-4

ISBN 978-3-322-95143-4 (eBook)

C 1999 Leske + Budrich, Opladen

Das Werk einschließlich aller seiner Teile ist urheberrechtlich geschützt. Jede Verwertung außerhalb der engen Grenzen des Urheberrechtsgesetzes ist ohne Zustimmung des Verlages unzulässig und strafbar. Das gilt insbesondere für Vervielfältigungen, Übersetzungen, Mikroverfilmungen und die Einspeicherung und Verarbeitung in elektronischen Systemen.

Satz: Leske + Budrich 


\section{Inhalt}

Vorwort

Ingo Kolboom

„Ich sehe das Frankreich des 21. Jahrhunderts...“.

Frankreichs Republik und Gesellschaft im Wandel

9

Themenschwerpunkt:

Krise des republikanischen Modells?

Marieluise Christadler

Neorepublikanismus gegen die Krise der Republik?............................... 31

Serge Berstein

Die beiden republikanischen Modelle Frankreichs im 20. Jahrhundert .. 57

Mariette Sineau

Zur Debatte über die Parität zwischen Männern und Frauen:

Argumente für eine neue Sicht der republikanischen Staatsbürgerschaft ...

Constanze von Krosigk

Laizität und republikanische Identität: Die Kopftuchaffäre als Auslöser und Ausdruck einer gesellschaftlichen Krise

François Beilecke

Diskursive Rehabilitierung des republikanischen Modells

und Neoliberalismus-Kritik in der französischen Presse seit 1990

\section{Roland Höhne}

Neorepublikanischer Diskurs und nationale Identität.

Eine aktuelle Kontroverse

Ingo Bode

Abschied vom Vorsorgestaat? Sozialpolitik und Zivilgesellschaft

à la française 
Andrea Szukala

Die Öffnung der politischen Entscheidungsprozesse in Frankreich:

ein Umbau des Staates in europäischer Absicht?

Beiträge

Wolfgang Asholt

Intellektuelle Faszination durch Frankreich.

Ist Frankreich noch interessant?

Kristina Schulz

Vom Buch zur „Bibel“ der Frauenbewegung:

„Das andere Geschlecht" in der Bundesrepublik Deutschland

179

Patrick Troude-Chastenet

Der Papon-Prozeß: Vichys ewige Wiederkehr?

195

Pia Le Moal-Piltzing

Lola rennt - aber filmisch läuft nicht mehr viel zwischen

Deutschland und Frankreich

\section{Dokumentation}

Chronik Mai 1998-Juni 1999 .................................................................. 225

Sozioökonomische Basisdaten im internationalen Vergleich ................. 239

Ergebnisse der Europawahlen vom Juni 1999........................................ 241

Deutschsprachige Literatur zu Frankreich.

Ausgewählte Neuerscheinungen 1998/1999 ..................................... 242

Abkürzungsverzeichnis .................................................................. 271

Personenregister ............................................................................. 273

$\mathrm{Zu}$ den Autoren ...................................................................... 278 


\section{Vorwort}

Der zwölfte Band des Frankreich-Jahrbuches, den wir hier vorlegen, bildet die Fortsetzung einer Initiative des „Arbeitskreises sozialwissenschaftliche deutsche Frankreichforschung" beim Deutsch-Französischen Institut.

Das Jahrbuch versteht sich als Beitrag der Wissenschaft zu besserer Frankreichkenntnis für eine größere Öffentlichkeit. Es ist also nicht als Sammelband für Spezialstudien angelegt. Diese sollen weiterhin dort erscheinen, wo sie hingehören: in den Zeitschriften der einzelnen Fachdisziplinen. Das Frankreich-Jahrbuch geht weiter. Es versucht, Zusammenhänge zu erschlieBen und sie so darzustellen, daß sie für alle diejenigen aufschlußreich sind, die sich in Politik, Wirtschaft, Kultur und Bildung mit französischen Fragen befassen oder sich ganz allgemein für unseren wichtigsten Nachbarn interessieren. Mit anderen Worten: Es will jenes Hintergrundwissen vermitteln, das zum Verständnis der Berichterstattung in den Medien, aber auch zur Erarbeitung eigener Stellungnahmen erforderlich ist. Daher wird das Jahrbuch kontroverse Meinungen, wie sie selbstverständlich auch unter FrankreichForschern bestehen, dokumentieren.

Die Erschließung von Zusammenhängen ist nur unter zwei Voraussetzungen möglich. Zum einen erfordert sie einen multidisziplinären Ansatz. Wir verstehen Frankreich-Forschung nicht sozialwissenschaftlich im engeren Sinn. Ohne Beiträge zur Geschichte, Philosophie, Literatur, Kunst und Alltagskultur ist die Entwicklung der französischen Gesellschaft nicht zu verstehen. Zum anderen wird es darum gehen, Frankreich nicht als freischwebende Monade (etwa aus der Sicht der sogenannten „Landeskunde“), sondern als integralen Bestandteil Westeuropas zu begreifen. Das bedeutet, neben den Eigenarten der französischen Problematik auch die Tendenzen zu untersuchen, die allgemeinerer Natur sind: Dies wirft Licht auf Strukturen, die der Alte Kontinent als Grundlage einer gemeinsamen Zukunft herauszubilden beginnt.

$\begin{array}{ll}\text { Die Herausgeber: } & \text { Lothar Albertin } \\ & \text { Wolfgang Asholt } \\ & \text { Hans Manfred Bock } \\ & \text { Marieluise Christadler } \\ & \text { Adolf Kimmel } \\ & \text { Ingo Kolboom } \\ & \text { Robert Picht } \\ & \text { Henrik Uterwedde }\end{array}$

